\title{
Correlation of Vocal Intensity with Velopharyngeal Closing Mechanism in Individuals with and without Complaint of Velopharyngeal Dysfunction
}

\author{
Karina Girelli ${ }^{1}$ Sady Selaimen de Costa $^{2}$ Marcus Vinícius Martins Collares ${ }^{3}$ Silvia Dornelles ${ }^{4}$
}

1 Master's Degree in Health of Children and Adolescents, Universidade
Federal do Rio Grande do Sul, Porto Alegre, Rio Grande do Sul, Brazil
2 Department of Ophthalmology and Otorhinolaryngology,
Universidade Federal do Rio Grade do Sul, Porto Alegre, RS, Brazil
${ }^{3}$ Department of Surgery, Universidade Federal do Rio Grade do Sul,
Porto Alegre, Rio Grande do Sul, Brazil
${ }^{4}$ Department of Health and Human Communication, Universidade
Federal do Rio Grade do Sul, Porto Alegre, Rio Grande do Sul, Brazil Int Arch Otorhinolaryngol 2016;20:18-24.
Address for correspondence Karina Girelli, MSc in Health of Children and Adolescents, Rua Júlio de Castilhos, 940, Centro, Farroupilha, 95180-000, Rio Grande do Sul, Brazil (e-mail: kgirelli@gmail.com).

\author{
Abstract \\ Keywords \\ - velopharyngeal \\ sphincter \\ - voice \\ - cleft lip \\ - cleft palate \\ - physiology
}

Introduction Velopharyngeal sphincter is a portion of the muscle of the palatopharyngeal arch that is capable of separating the oral cavity from the nasal cavity. It has not been determined yet whether voice intensity has an influence on this capacity. Velopharyngeal sphincter closure is accomplished by elevating and retracting the soft palate at the same time as the nasopharyngeal walls are constricted.

Objective This study aims to correlate voice intensity with velopharyngeal sphincter closure in individuals without velopharyngeal dysfunction and patients with cleft lip and palate.

Methods We conducted a cross-sectional, comparative, and contemporary study. The sample consisted of 16 individuals in the control group and 16 individuals in the study group. Patients underwent instrumental assessment, which we subsequently analyzed using a computer program, and a brief medical history review. The mean age of the control group was 27.6 years, whereas the mean age of the case group was 15.6 years. Results Cases showed higher voice intensity in regular and weak fricative sentences when compared with controls. There was no agreement on the analysis of the instrumental assessment between the assessors and the computer program. Regardless of voice intensity, the computer program demonstrated a similar closure pattern. Conclusion The computer program showed similar closure pattern for the three levels of intensity. There was no agreement between the three assessors and the closure pattern determined by the computer program. There was no statistically significant correlation between voice intensity and degree of velopharyngeal sphincter closure. received

January 28, 2015 accepted

August 31, 2015

published online

November 24, 2015
DOI http://dx.doi.org/

10.1055/s-0035-1567809. ISSN 1809-9777.
Copyright $(2015$ by Thieme Publicações License terms

Ltda, Rio de Janeiro, Brazil
(ब(1) $\Theta \circledast$ 


\section{Introduction}

The velopharyngeal sphincter functions as a valve that closes like a sphincter. It extends along the lateral and posterior pharyngeal walls and its anterior boundary is close to the soft palate. ${ }^{1-5}$ Velopharyngeal sphincter closure is accomplished by elevating and retracting the soft palate at the same time as the nasopharyngeal walls are constricted. ${ }^{3,6,7}$ The primary function of the velopharyngeal sphincter is to ensure the physiological maintenance of this region. ${ }^{1,8}$

Speech may be affected in different ways when the velopharyngeal closure pattern is disturbed. The most common symptoms of velopharyngeal inadequacy are hypernasality, nasal air escape, and articulation problems. However, all these symptoms depend on how much the soft palate has been affected. ${ }^{9}$

Malfunctioning of the velopharyngeal closure mechanism, which constitutes the velopharyngeal dysfunction, may be associated with several underlying diseases such as neurological disorders, sequelae from surgical interventions, structural changes, etc. Malformations in the palate region lead to physiological abnormalities in the velopharyngeal sphincter, such as characteristics of cleft lip and palate. ${ }^{10}$

The speech and voice inadequacy caused by velopharyngeal insufficiency is a major stigma of patients with cleft palate. ${ }^{11}$ Several abnormal characteristics that impair communication can be detected in the speech of such individuals. ${ }^{12}$ Primary and secondary speech disorders relate to velopharyngeal dysfunction. Hypernasality and nasal air escape are primary disorders, whereas compensatory articulation and its associated facial movement are secondary disorders. ${ }^{13}$

Velopharyngeal dysfunction is a term used to describe abnormalities in the velopharyngeal mechanism in general; nevertheless, different terms are common to describe different disorders. Velopharyngeal insufficiency has a structural cause; the soft palate movement is normal, but it is too short to accomplish velopharyngeal closure. Another type of velopharyngeal dysfunction is velopharyngeal incompetence, which is caused by a neuromotor disorder; the soft palate has a normal structure, although it does not move sufficiently to achieve velopharyngeal closure. ${ }^{5,14-16}$ Failure of velopharyngeal closure may persist even after surgical repair of the palate. ${ }^{17}$

Understanding the physiology of the craniofacial structures affected by this disease is essential to choose the most appropriate therapeutic modality. The region of the velopharyngeal sphincter is the most difficult for understanding the pathophysiology of the functional changes present in this malformation. ${ }^{8}$

There are few studies in literature correlating velopharyngeal closure with regular, weak, or strong voice intensity. Therefore, the objective of the present study was to evaluate this association, comparing the three voice intensities produced by patients without velopharyngeal dysfunction and patients with cleft lip and palate.

\section{Methods}

We conducted a cross-sectional, comparative, and contemporary study. The Scientific Committee and Research Ethics Committee evaluated and approved the project (protocol no. 13-0360).
Considering a 95\% confidence level, an estimated standard deviation at $7 \%$ of the percentage of velopharyngeal closure, and a margin of error of $5 \%$, we included 27 individuals in each group. This sample size calculation was based on the dissertation by Dornelles. Nevertheless, we evaluated 32 individuals in the control group; however, 16 tests were not properly recorded due to technical equipment failure. In the case group, we could not achieve the size initially calculated for the sample because of the long period of routine patient care. Therefore, after applying the inclusion and exclusion criteria, we selected 16 patients for the control group and 16 patients for the case group. The participants voluntarily agreed to participate in the study.

According to the inclusion criteria, we included in the control group female and male participants without velopharyngeal dysfunction, whose age ranged from 18 to 50 years old. The case group included female and male participants with velopharyngeal dysfunction and cleft lip and palate, aged 7 to 51 years, who had undergone repair surgeries and were receiving follow-up at the Outpatient Clinic of Otolaryngology and Cleft Lip and Palate between March and July 2014.

We excluded individuals who (or whose guardians) did not agree to participate in the study by not signing the informed consent form, as well as patients with cognitive and/or behavioral disorders with associated syndromes, individuals with dysphonia, use of nasoenteric tube that could prevent or hinder the performance of videonasoendoscopy, and patients with anatomical and functional abnormalities that prevented the performance of routine examinations and clinical follow-up.

We searched the speech-screening database for the patients' medical history. We also conducted brief interviews with the participants and/or their guardians. For those who agreed to participate in the study, we performed videonasoendoscopy examination with flexible fiber to the area of the velopharyngeal sphincter to capture images of the studied structures. The survey had a standardized dynamic, better access to nostril without anesthetic, with the patient sitting in front of the medical examiner. The examiner recorded a speech sample consisting of two sentences at three different intensities: regular, weak, and strong. The sentences contained plosive sounds (Papai pediu pipoca, Dad asked for popcorn) and fricative sounds (Juju saiu cedo, Juju left early). Actual intensities were computed in accordance with what was requested and measured by the DL decibel meter, Model 4020 (ICEL, Manaus). The microphone was positioned $5 \mathrm{~cm}$ away from the subject́s mouth, in his lapel. Before starting the exam, the examiner measured environmental noise. The patient was asked to perform the steps in the assigned protocol, under constant monitoring by the researcher in charge. For the videonasoendoscopy procedure, we used equipment belonging to the Otorhinolaryngology Department. We edited the images to include the two sentences at the three different intensities, recorded them on DVD, and showed them to three professionals experienced in the assessment and treatment of patients with cleft lip and palate. The audio was deleted from the video records and the 
assessors were supposed to rate each sentence according to the appropriate closure (similar closure pattern, large gap, small gap, and moderate gap). Next, we analyzed images using a computer program that is under improvement, used only in research aiming to analyze their actual contributions in the same. We used a computational model for the analysis of the wall motion of the velopharyngeal sphincter.

The quantitative variables were expressed as mean and standard deviation, whereas the qualitative variables were expressed as absolute and relative frequencies. We used student's $t$-test and Fisher's exact test to compare the means between the groups. To calculate the clinical estimate of the velopharyngeal sphincter closure, we reached agreement between the analyses of the three assessors considering the whole sample. As there was no agreement using the Kappa test, we used the analysis of the assessors with greater scientific and technical knowledge in the field as a reference for data analysis. We also evaluated the agreement produced by the computer program using the Kappa test. We performed the interpretation of Kappa coefficients as proposed by Landis and Koch. Kappa values may range from 1 (perfect agreement) to $<0$ (no agreement). The authors proposed a six-level scale so that the values $<0$ indicated no agreement, the values from 0.00 to 0.20 showed very poor agreement, from 0.21 to 0.40 showed poor agreement, from 0.41 to 0.60 showed moderate agreement, from 0.61 to 0.80 showed good agreement, and from 0.81 to 1.00 showed perfect or almost perfect agreement. We evaluated the association between the intensity of the sentences of velopharyngeal sphincter closure between the assessors and the computer program using Spearman's correlation coefficient. We compared the proportions between groups using Pearson's chi-square test and Fisher's exact test. In both analyses, we used a significance level of 5\%, and the SPSS version 18.0 for the analyses.

\section{Results}

Thirty-two individuals participated in the study: 16 in the control group and 16 in the case group. In the control group, 12 (75\%) participants were female and four (25\%) were male; their mean age was 27.6 years $( \pm 9.5)$, ranging between 18 and 51 years old. In the case group, eight (50\%) participants were female and eight (50\%) were male; their mean age was 15.6 years $( \pm 11.5)$, ranging between 7 and 50 years old.

In the case group, the participants had cleft lip and palate. Based on the classification suggested by Brazil Cleft, we found higher prevalence of unilateral cleft lip and palate $(7 ; 43.75 \%)$ and lower frequency of unilateral cleft lip $(0 ; 0 \%)$, followed by full cleft palate $(4 ; 25 \%)$, bilateral cleft lip and palate (3; 18.75\%), and bilateral cleft lip and incomplete cleft palate (1; 6.25\%). All participants had undergone previous surgery. Eleven (68.75\%) underwent nose and lip repair surgery, 15 (93.75\%) underwent palate repair surgery, and one (6.25\%) underwent pharyngeal flap surgery.

- Table 1 shows the characteristics of the sample. Controls were significantly older than cases. There was no difference between the groups in terms of gender.
Table 1 Characteristics of the sample

\begin{tabular}{|l|l|l|l|}
\hline Variables & Cases & Controls & P \\
\hline $\begin{array}{l}\text { Age (years) } \\
- \text { Mean } \pm \text { SD }\end{array}$ & $15.6 \pm 11.5$ & $27.6 \pm 9.5$ & $0.003^{*}$ \\
\hline Gender $-\mathbf{n}(\%)$ & - & - & $0.273^{* *}$ \\
\hline Male & $8(50.0)$ & $4(25.0)$ & - \\
\hline Female & $8(50.0)$ & $12(75.0)$ & - \\
\hline
\end{tabular}

*Student's t-test;

${ }^{* *}$ Fisher's exact test.

- Table 2 shows that patients had higher voice intensity (which was measured using a decibel meter) in the regular and weak fricative sentences when compared with the control group, showing a statistically significant relationship.

- Table 3 shows the agreement between the assessors in terms of intensity and velopharyngeal sphincter closure. There was significant agreement between assessors 2 and 3 considering the plosive sentence at regular and strong intensity. However, these agreements were weak according to Landis and Koch. There was also significant agreement between assessors 1 and 3 regarding all intensities of the plosive sentence and in terms of the regular intensity of the fricative sentence. Of the four variables showing agreement, one (25\%) was very weak, two (50\%) were weak, and one (25\%) was moderate (plosive sentence at strong intensity).

- Table 4 shows the association between the intensity of the sentences and the closure according to assessor 1 and the computer program. There was no significant association between the intensity of the sentences and closure both according to the assessors and the computer program; that is, regardless of the intensity, closure remained similar.

- Table 5 shows data on the agreement between the assessors and the computer program in terms of velopharyngeal sphincter closure. There was no significant agreement between the assessors and the computer program.

Table 2 Comparison of voice intensity between cases and controls according to the decibel meter

\begin{tabular}{|l|l|l|l|}
\hline Variables & $\begin{array}{l}\text { Cases } \\
\text { Mean } \pm \text { SD }\end{array}$ & $\begin{array}{l}\text { Controls } \\
\text { Mean } \pm \text { SD }\end{array}$ & $\mathbf{p}^{*}$ \\
\hline Plosive sentence & & & \\
\hline Regular & $73.8 \pm 3.2$ & $70.9 \pm 4.7$ & 0.053 \\
\hline Weak & $69.6 \pm 3.5$ & $70.6 \pm 6.7$ & 0.602 \\
\hline Strong & $79.9 \pm 6.3$ & $82.4 \pm 7.8$ & 0.325 \\
\hline Fricative sentence & & & \\
\hline Regular & $74.2 \pm 3.9$ & $70.3 \pm 2.9$ & 0.003 \\
\hline Weak & $70.6 \pm 4.1$ & $67.1 \pm 2.2$ & 0.005 \\
\hline Strong & $79.4 \pm 6.1$ & $77.9 \pm 6.6$ & 0.529 \\
\hline
\end{tabular}

*Student's t-test. 
Table 3 Agreement between assessors

\begin{tabular}{|c|c|c|c|c|}
\hline Comparisons & SCP/LG/SG/MG \% & Agreement (\%) & Kappa & $\mathrm{p}$ \\
\hline \multicolumn{5}{|c|}{ Assessor 1 versus Assessor 2} \\
\hline \multicolumn{5}{|l|}{ Plosive sentence } \\
\hline Regular intensity & $65.6 / 0 / 21.9 / 12.5$ versus $56.3 / 12.5 / 21.9 / 9.4$ & $15 / 32=46.8 \%$ & 0.13 & 0.377 \\
\hline Weak intensity & $68.8 / 12.5 / 6.3 / 12.5$ versus $46.9 / 15.6 / 18.8 / 18.8$ & $13 / 32=40.6 \%$ & 0.05 & 0.647 \\
\hline Strong intensity & $53.1 / 28.1 / 18.8 / 0$ versus $40.6 / 34.4 / 15.6 / 9.4$ & $16 / 32=50.0 \%$ & 0.29 & 0.033 \\
\hline \multicolumn{5}{|l|}{ Fricative sentence } \\
\hline Regular intensity & $68.8 / 6.3 / 12.5 / 12.5$ versus $40.6 / 18.8 / 18.8 / 21.9$ & $17 / 32=53.1 \%$ & 0.29 & 0.003 \\
\hline Weak intensity & $71.9 / 12.5 / 15.6 / 0$ versus $53.1 / 9.4 / 31.3 / 6.3$ & $19 / 32=59.3 \%$ & 0.18 & 0.161 \\
\hline Strong intensity & $75 / 12.5 / 3.1 / 9.4$ versus $40.6 / 40.6 / 6.3 / 12.5$ & $15 / 32=46.8 \%$ & 0.16 & 0.109 \\
\hline \multicolumn{5}{|c|}{ Assessor 2 versus Assessor 3} \\
\hline \multicolumn{5}{|l|}{ Plosive sentence } \\
\hline Regular intensity & $56.3 / 12.5 / 21.9 / 9.4$ versus $56.3 / 12.5 / 25 / 6.3$ & $17 / 32=53.1 \%$ & 0.23 & 0.050 \\
\hline Weak intensity & $46.9 / 15.6 / 18.8 / 18.8$ versus $53.1 / 12.5 / 12.5 / 21.9$ & $15 / 32=46.8 \%$ & 0.20 & 0.059 \\
\hline Strong intensity & $40.6 / 34.4 / 15.6 / 9.4$ versus $46.9 / 34.4 / 6.3 / 12.5$ & $17 / 32=53.1 \%$ & 0.30 & 0.008 \\
\hline \multicolumn{5}{|l|}{ Fricative sentence } \\
\hline Regular intensity & $40.6 / 18.8 / 18.8 / 21.9$ versus $25 / 6.3 / 37.5 / 31.3$ & $7 / 32=21.8 \%$ & -0.04 & 0.649 \\
\hline Weak intensity & $53.1 / 9.4 / 31.3 / 6.3$ versus $28.1 / 15.6 / 28.1 / 28.1$ & $6 / 32=18.7 \%$ & -0.11 & 0.244 \\
\hline Strong intensity & $40.6 / 40.6 / 6.3 / 12.5$ versus $25 / 53.1 / 9.4 / 12.5$ & $12 / 32=37.5 \%$ & 0.06 & 0.630 \\
\hline \multicolumn{5}{|c|}{ Assessor 1 versus Assessor 3} \\
\hline \multicolumn{5}{|l|}{ Plosive sentence } \\
\hline Regular intensity & $65.6 / 0 / 21.9 / 12.5$ versus $56.3 / 12.5 / 25 / 6.3$ & $18 / 32=56.2 \%$ & 0.32 & 0.027 \\
\hline Weak intensity & $68.8 / 12.5 / 6.3 / 12.5$ versus $53.1 / 12.5 / 12.5 / 21.9$ & $18 / 32=56.2 \%$ & 0.25 & 0.021 \\
\hline Strong intensity & $53.1 / 28.1 / 18.8 / 0$ versus $46.9 / 34.4 / 6.3 / 12.5$ & $19 / 32=59.3 \%$ & 0.47 & 0.001 \\
\hline \multicolumn{5}{|l|}{ Fricative sentence } \\
\hline Regular intensity & $68.8 / 6.3 / 12.5 / 12.5$ versus $25 / 6.3 / 37.5 / 31.3$ & $13 / 32=40.6 \%$ & 0.20 & 0.022 \\
\hline Weak intensity & $71.9 / 12.5 / 15.6 / 0$ versus $28.1 / 15.6 / 28.1 / 28.1$ & $12 / 32=37.5 \%$ & 0.22 & 0.067 \\
\hline Strong intensity & $75 / 12.5 / 3.1 / 9.4$ versus $25 / 53.1 / 9.4 / 12.5$ & $11 / 32=34.3 \%$ & 0.10 & 0.193 \\
\hline
\end{tabular}

*Abbreviations: LG, Large gap; MG, Moderate gap; SCP, Similar closure pattern; SG, Small gap.

Table 4 Association between sentence intensity and closure according to the assessor and the computer program using Spearman's correlation coefficient

\begin{tabular}{|l|l|l|l|l|}
\hline Intensity of the sentences & \multicolumn{2}{l|}{ Case group } & \multicolumn{2}{l|}{ Control group } \\
\hline & Assessor & Computer program & Assessor & Computer program \\
\hline Plosive sentence & & & & \\
\hline Regular & 0.120 & -0.196 & -0.320 & $*$ \\
\hline Weak & 0.029 & 0.214 & 0.181 & $*$ \\
\hline Strong & 0.296 & -0.169 & 0.416 & $*$ \\
\hline Fricative sentence & & & & \\
\hline Regular & -0.267 & 0.206 & 0.197 & $*$ \\
\hline Weak & -0.049 & -0.235 & -0.072 & $*$ \\
\hline Strong & -0.085 & 0.185 & -0.366 & $*$ \\
\hline
\end{tabular}

\footnotetext{
* We could not perform statistical test because all controls showed similar closure pattern according to the computer program.
} 
Table 5 Agreement between assessors and computer program

\begin{tabular}{|l|l|l|l|l|}
\hline Comparisons & $\begin{array}{l}\text { SCP/LG/ } \\
\text { SG/MG \% }\end{array}$ & Agreement (\%) & Kappa & P \\
\hline Assessors versus Computer program & & & \\
\hline Plosive sentence & & $20 / 32=62.5 \%$ & -0.07 & 0.586 \\
\hline Regular intensity & $65.6 / 0 / 21.9 / 12.5$ versus $93.8 / 3.1 / 3.1 / 0$ & $22 / 32=68.7 \%$ & 0.18 & 0.131 \\
\hline Weak intensity & $68.8 / 12.5 / 6.3 / 12.5$ versus $93.8 / 0 / 3.1 / 3.1$ & $17 / 32=53.1 \%$ & 0.06 & 0.634 \\
\hline Strong intensity & $53.1 / 28.1 / 18.8 / 0$ versus $93.8 / 6.3 / 0 / 0$ & & & \\
\hline Fricative sentence & & $21 / 32=65.6 \%$ & 0.02 & 0.838 \\
\hline Regular intensity & $68.8 / 6.3 / 12.5 / 12.5$ versus $93.8 / 0 / 3.1 / 3.1$ & $22 / 32=68.7 \%$ & -0.06 & 0.713 \\
\hline Weak intensity & $71.9 / 12.5 / 15.6 / 0$ versus $93.8 / 3.1 / 0 / 3.1$ & & -0.06 & 0.678 \\
\hline Strong intensity & $75 / 12.5 / 3.1 / 9.4$ versus $93.8 / 6.3 / 0 / 0$ & $23 / 32=71.8 \%$ & &
\end{tabular}

*Abbreviations: LG, Large gap; MG, Moderate gap; SCP, Similar closure pattern; SG, Small gap.

\section{Discussion}

The velopharyngeal closure is the result of the action of a set of muscles. That is, it consists of a mechanism that works in a coordinated and synergic manner to alternately bring together or separate the oropharyngeal and nasopharyngeal cavities. $^{18,19}$ This mechanism is essential for the production of vowels and consonants; therefore, it has a profound impact on speech intelligibility. Several clinical populations, such as children with a history of cleft lip and palate or individuals with dysarthria, have velopharyngeal dysfunctions that cause speech production difficulties. ${ }^{20}$

The main objective of the present study was to compare voice intensity and velopharyngeal sphincter closure. Our sample consisted of individuals with and without velopharyngeal dysfunction and patients with cleft lip and palate. The most frequent dysfunction was unilateral cleft lip and palate. Given that we used a random sample and there was no case of unilateral cleft lip, we regrouped the types of cleft. The most prevalent cases were cleft lip and palate. Such data are consistent with the literature..$^{21-23}$ The second most common type was cleft lip, and the least prevalent type was cleft palate.

Our findings demonstrated that controlpatients were significantly older than patients. The control grouṕs mean age was 27.6 years, whereas the case grouṕs mean age was 15.6 years. The velopharyngeal sphincter is critical for successful feeding and communication. Motor activities, such as speech, sucking, swallowing, gag reflex, and breathing, need a point of maximum closure during the movement against the walls. ${ }^{2,24-26}$ We could not find many studies describing aspects of voice, swallowing, and hearing including anatomical and functional signs and functional decline in the literature. However, previous studies have not found deterioration of velopharyngeal functions with aging. 27,28

We assessed all patients using videonasoendoscopy. We used a decibel meter to measure the voice intensity of the fricative and plosive sentences. We found that cases had higher intensities in regular and weak fricative sentences when compared with controls. Fricative and plosive phonemes are included in the protocol because they require greater intraoral pressure; therefore, they evidence the articulation difficulties of patients with cleft. ${ }^{29,30}$

The authors, ${ }^{31}$ in their study on the variation of voice intensity, found mean voice intensity of $63.4 \mathrm{~dB}$ at regular emission and $72.5 \mathrm{~dB}$ at high emission. Such findings are not in agreement with the present study. In our study, the mean intensities were higher. The participants of the case group had mean voice intensities of 73.8 and $79.9 \mathrm{~dB}$ for the plosive sentence, and 74.2 and $79.4 \mathrm{~dB}$ for the fricative sentence; whereas, the participants of the control group showed mean intensities of 70.9 and $82.4 \mathrm{~dB}$ for the plosive sentence and 70.3 and $77.9 \mathrm{~dB}$ for the fricative sentence.

With the purpose of achieving the objectives of the study, we calculated the agreement between the assessors for the velopharyngeal sphincter closure patterns using the Kappa coefficient of agreement by pairing the findings of an assessor with each of the other assessors, thus resulting in three pairs $(1 \times 2,2 \times 3,1 \times 3)$. We only found six variables showing agreement; and of these, one had very weak intensity, one had moderate intensity, and four had weak intensity. Assessments of auditory perception are known to be unreliable ${ }^{32}$ and are not necessarily correlated with the functioning of the velopharyngeal sphincter. ${ }^{33-35}$ Therefore, the decisions of the auditory perception regarding the velopharyngeal function are often complemented by instrumental evaluation. ${ }^{20}$

As demonstrated in the present study, there was no statistically significant relationship between the intensity of the sentences and velopharyngeal sphincter closure, regardless of the fact that the intensity of the closure pattern remained similar. In another study, the authors have reported that the orifice of the velopharyngeal sphincter does not become smaller when there is increased intensity. ${ }^{36}$ Therefore, this may indicate that the speaker is already using the physiological mechanisms to achieve maximum closure. These authors also stated that these results demonstrate the use of high voice intensity as a strategic behavior for individuals with poor performance of the velopharyngeal sphincter and/or hypernasality. ${ }^{36}$ The authors ${ }^{26}$ performed a study of 21 assessments aimed at investigating whether the 
nasal emission test showed compatibility with the videonasoendoscopy findings in the evaluation of the velopharyngeal mechanism. They found that the participants did not show articulatory compensation and had large gaps in most productions of phonemes, tending to maintain the same gap size in both plosive and fricative sentences. This is an interesting find because it shows that it is possible to produce sounds without compensation, even when there is velopharyngeal incompetence or insufficiency.

Although videonasoendoscopy allows us to view the velopharyngeal sphincter during speech, the test has some limitations. It is an invasive method and has the disadvantage of being subjective because it does not provide quantitative data, with arbitrary inference of velopharyngeal gap size. ${ }^{37}$ In the present study, there was not agreement between the assessors and the computer program. The velopharyngeal sphincter closure assessed by the computer program was similar in both groups, with no difference between the proportions found. However, it is worth noting that the only two patients who had no such closure pattern were in the case group. Therefore, it is important to standardize the assessment, so that more objective data can be collected regarding the evaluation of the motion of the velopharyngeal sphincter.

Many researchers have concluded that the velopharyngeal mechanism is highly complex and, thus, it can only be understood if several images are combined due to the difficulties in getting a general view of the area. ${ }^{38,39}$ The need for accurate information about the closure patterns is considered vital for planning surgical intervention ${ }^{40,41}$ and enabling the assessment of the advances of surgical methods. ${ }^{42}$

With respect to the sample size, we performed calculations. However, we could not include it due to the routine care front upon which the project depended and the deadline for completion of the work. Nevertheless, we believe that it has not generated a false negative, based on clinical experience coupled with years of observation. We believe that our study may help to understand the velopharyngeal function by providing more reliable clinical evaluation tools.

\section{Conclusions}

When the three voice intensities (regular, strong, and weak) related to velopharyngeal sphincter closure, regardless of whether the patient had velopharyngeal dysfunction, the computer program showed similar closure pattern. Thus, it proved to be a useful tool in clinical practice to assess the functioning of the velopharyngeal sphincter.

There was no statistically significant correlation between voice intensity of speech and degree of velopharyngeal sphincter closure in both groups. Based on our results, there was no agreement between the three assessors regarding the velopharyngeal sphincter closure pattern. Because perceptual analysis are often not reliable, there is need for standardization of a protocol or a tool to assist in this assessment.

We could not establish a correlation between the groups with and without velopharyngeal dysfunction in terms of closure mechanism and voice intensity. It was not possible correlate the findings in both groups with clinical practice. Therefore, we suggest using a larger sample size to check our findings. In addition, further studies should be conducted on this topic to contribute to increase scientific knowledge.

\section{References}

1 Altmann EBC. Anatomia e fisiologia do esfíncter velofaríngeo. In: Altmann EBC. Fissuras labiopalatinas. 4 ed. Carapicuíba: Pró-Fono; 1997:133-156

2 Camargo LOS, Rodrigues CM, Avelar JA. Oclusão velofaríngea em indivíduos submetidos à nasoendoscopia na Clínica de Educação para Saúde (CEPS). Salusvita. 2001;20(1):35-47

3 Souza MCQ. . Características espectrais da nasalidade [Dissertation]. São Paulo: Universidade de São Paulo; 2003

4 Carrara -de Angelis E. Voz nos distúrbios neurológicos. In: Ferreira LP, Befi-Lopes DM, Limongi SCO. Tratado de Fonoaudiologia. São Paulo: Roca; 2005:75-90

5 Kummer AW. Speech evaluation for patients with cleft palate. Clin Plast Surg 2014;41(2):241-251

6 Zemlin WR. Princípios de Anatomia e Fisiologia em Fonoaudiologia. São Paulo: Artmed; 2002

7 Cheng N, Zhao M, Qi K, Deng H, Fang Z, Song R. A modified procedure for velopharyngeal sphincteroplasty in primary cleft palate repair and secondary velopharyngeal incompetence treatment and its preliminary results. J Plast Reconstr Aesthet Surg 2006;59(8):817-825

8 Silva DP, Dornelles S, Paniagua LM, Da Costa SS, Collares MVM. Aspectos patofisiológicos do esfíncter velofaríngeo nas fissuras palatinas. Int Arch Otorhinolaryngol. 2008;12(3):426-435

9 Trindade IEK, Trindade Junior AS. Avaliação funcional da inadequação velofaríngea. In: Carreirrão S, Lessa S, Zanini AS. Tratamento das fissuras labiopalatinas. 2 ed. Rio de Janeiro: Revinter; 1996

10 Brunner MB, Stellzig-Eisenhauer A, Pröschel U, Verres R, Komposh G. The effect of nasopharngoscopic biofeedback in patients with cleft palate and velopharyngeal dysphunction. Clef Palate Craniofacial J. 2005:649-657

11 Araujo Netto BC, Cervantes O. Estudo comparativo entre pacientes fissurados portadores de insuficiência velofaríngea tratados com fonoterapia e faringoplastia. . Rev Bras Cir Plast. 2011;26(4): 631-638

12 Palandi BBN, Guedes ZCF. Aspectos of speech of subjects with cleft palate corrected in different ages. Rev CEFAC 2011;13(1): 8-16

13 Henningsson G, Kuehn DP, Sell D, Sweeney T, Trost-Cardamone JE, Whitehill TL; Speech Parameters Group. Universal parameters for reporting speech outcomes in individuals with cleft palate. Cleft Palate Craniofac J 2008;45(1):1-17

14 Trost-Cardamone JE. Coming to terms with VPI: a response to Loney and Bloem. Cleft Palate J 1989;26(1):68-70

15 Trindade IEK, Yamashita RP, Gonçalves CGA. Diagnóstico Instrumental da disfunção velofaríngea. In: Trindade IEK, Silva Filho OG. Fissuras labiopalatinas: uma abordagem interdisciplinar. São Paulo: Editora Santos; 2007:123-143

16 Pegoraro-Krook MI, Dutka-Souza JCR, Magalhães LCT, Feniman MR. Intervenção fonoaudiológica na fissura palatina. In: Ferreira LP, Befi-Lopes DM, Limongi SCO. Tratado de fonoaudiologia. 2ed. São Paulo: Roca; 2010:439-455

17 Mituuti CT, Piazentin-Penna SHA, Brandão GR, Bento-Gonçalves CGA. Characterization of the speech of individuals submitted to primary palatoplasty. Rev Soc Bras Fonoaudiol. 2010;15(3): 355-361

18 Cassell MD, Elkadi H. Anatomy and Physiology of the palate and Velopharyngeal structures. In: Shprintzen RJ, Bardach J. Cleft 
Palate Speech Management: A Multidisciplinary Approach. St Louis: Mosby; 1995:45-58

19 Tabith Junior A. Lesões congênitas de lábio e palato - fissuras labiopalatinas. . In: Tabith Junior A. Foniatria: disfonias, fissuras labiopalatais e paralisia cerebal. 6 ${ }^{\underline{a}}$ ed. São Paulo: Cortez; 1997

20 Bunton K, Hoit JD, Gallagher K. A simple technique for determining velopharyngeal status during speech production. Semin Speech Lang 2011;32(1):69-80

21 Monlleó IL, Fontes MIB, Ribeiro EM, De Souza J, Leal GF, Félix TM, Fett-Conte AC, Bueno BH, Magna LA, Mossey PA, Gil-da Silva-Lopes V. Implementing the Brazilian Database on Orofacial Clefts. Plastic Surgery International 2013;2013:1-10

22 Souza J, Raskin S. Clinical and epidemiological study of orofacial clefts. J Pediatr (Rio J) 2013;89(2):137-144

23 Martelli DR, Machado RA, Swerts MSO, Rodrigues LAMR, Aquino SN, Martelli Júnior H. Non syndromic cleft lip and palate: relationship between sex and clinical extension. Braz J Otorhinolaryngol 2012;78(5):116-120

24 Nóbrega ESS. Fissuras Palatais. In: Mélega JM. Cirurgia Plástica Fundamentos e Arte- Cirurgia reparadora da cabeça e pescoço. Rio de Janeiro Medsi 2002:110-125

25 Mourão D, Souza GS, Torres LV, Vaz RN, Prado SG. Estudo sobre desenvolvimento fonológico em fissurados: implicações na fala e na linguagem. Estudos 2006;33(5/6):425-441

26 Penido FA, Noronha RM, Caetano KI, Jesus MS, Di Ninno CQ Britto AT. Correlação entre os achados do teste de emissão de ar nasal e da nasofaringoscopia em pacientes com fissura labiopalatina operada. Rev Soc Bras Fonoaudiol 2007;12(2): 126-134

27 Hoit JD, Watson PJ, Hixon KE, McMahon P, Johnson CL. Age and velopharyngeal function during speech production. J Speech Hear Res 1994;37(2):295-302

28 Zajac DJ. Velopharyngeal function in young and older adult speakers: evidence from aerodynamic studies. J Acoust Soc Am 1997; 102(3):1846-1852

29 Eckelmann D, Baldridge P. Speech training for a child with cleft palate. J Speech Disord 1945;10:137-149
30 Trost JE. Articulatory additions to the classical description of the speech of persons with cleft palate. Cleft Palate J 1981;18(3): 193-203

31 Koishi HU, Tsuji DH, Imamura R, Sennes LU. Variação da intensidade vocal: estudo da vibração das pregas vocais em seres humanos com videoquimografia. Rev Bras Otorrinolaringol (Engl Ed) 2003;69(4):464-470

32 Bradford LJ, Brooks AR, Shelton RL Jr. Clinical judgments of hypernasality in cleft palate children. Cleft Palate J 1964;35:329-335

33 Mayo R, Dalston RM, Warren DW. Perceptual assessment of resonance distortion in unoperated clefts of the secondary palate. Cleft Palate Craniofac J 1993;30(4):397-400

34 Warren DW, Dalston RM, Mayo R. Hypernasality and velopharyngeal impairment. Cleft Palate Craniofac J 1994;31(4):257-262

35 Watterson T, Emanuel F. Observed effects of velopharyngeal orifice size on vowel identification and vowel nasality. Cleft Palate J 1981; 18(4):271-278

36 Young LH, Zajac DJ, Mayo R, Hooper CR. Effects of vowel height and vocal intensity on anticipatory nasal airflow in individuals with normal speech. J Speech Lang Hear Res 2001;44(1):52-60

37 Yamashita RP, Oliva TRT, Fukushiro AP, Brustello CMB, Trindade IEK. Efeito da velopastia intravelar sobre o fechamento velofaríngeo avaliado por meio da técnica fluxo-pressão. Rev Soc Bras Fonoaudiol. 2010;15(3):362-368

38 Skolnick ML, McCALL GN, Barnes M. The sphincteric mechanism of velopharyngeal closure. Cleft Palate J 1973;10:286-305

39 Shprintzen RJ. An invited commentary on the preceding article by Ibuki, Karnell and Morris. Cleft Palate J 1983;20:105-107

40 Pigott RW, Makepeace AP. Some characteristics of endoscopic and radiological systems used in elaboration of the diagnosis of velopharyngeal incompetence. Br J Plast Surg 1982;35(1):19-32

41 Croft CB, Shprintzen RJ, Rakoff SJ. Patterns of velopharyngeal valving in normal and cleft palate subjects: a multi-view videofluoroscopic and nasendoscopic study. Laryngoscope 1981;91(2):265-271

42 Havstam C, Lohmander A, Persson C, Dotevall H, Lith A, Lilja J. Evaluation of VPI-assessment with videofluoroscopy and nasoendoscopy. Br J Plast Surg 2005;58(7):922-931 